\title{
Growth inhibition of Tax-activated human Jurkat leukemia T cells by all-trans retinoic acid requires JNK-1 inhibition
}

\author{
EDUARDO PARRA $^{1}$ and LUIS GUTIÉRREZ ${ }^{2}$ \\ ${ }^{1}$ Biomedical Experimental Laboratory, Faculty of Sciences, University of Tarapaca, Arica; \\ ${ }^{2}$ Faculty of Sciences, Arturo Prat University, Iquique, Chile
}

Received August 17, 2012; Accepted October 2, 2012

DOI: $10.3892 /$ or.2012.2108

\begin{abstract}
Retinoids, including vitamin A (retinol) and its analogues, are critical for a variety of biological functions. In this study, we report that all-trans retinoic acid (ATRA) decreases Jun N-terminal kinase 1 (JNK-1) activity, antagonizing the effect of the Tax protein in Jurkat leukemia T cells transiently transfected for expressing the Tax protein. The Tax protein is one of the products of the human T-cell leukemia virus type 1 (HTLV-1) which is the etiologic agent of adult T-cell leukemia (ATL), an aggressive neoplasia of $\mathrm{CD}^{+}$ $\mathrm{T}$ cells. The decrease in JNK-1 activity was followed by a marked decrease in the expression of interleukin (IL)-2 and a weak increase in interferon (IFN)- $\gamma$ in Jurkat cells treated with ATRA in a dose-dependent manner, suggesting a correlation between the expression of JNK-1 and the activity of the Tax protein. However, the expression levels of IL-4 and IL-10 were enhanced in cells transfected with Tax, compared with the levels in untransfected cells, but the expression levels were not affected following ATRA treatment. In transfection studies using a luciferase reporter construct expressing the IL-2 promoter or a tandem repeat of AP- 1 or $\mathrm{NF}-\kappa \mathrm{B}$, the inhibitory effect of ATRA on the IL-2 promoter and AP-1 construct was confirmed at the transcriptional level. However, the inhibitory effect in the NF- $\kappa \mathrm{B}$ reporter construct was only marginal. In addition, our data demonstrated that JNK-1 is constitutively activated in Jurkat leukemia T cells expressing the Tax protein, suggesting that JNK-1 is required for Tax-induced proliferation of Jurkat leukemia cells.
\end{abstract}

\section{Introduction}

Human T-cell leukemia virus type 1 (HTLV-1) is the etiologic agent of adult T-cell leukemia (ATL), an aggressive neoplasia of $\mathrm{CD}^{+} \mathrm{T}$ cells $(1,2)$. The HTLV-1 transcriptional

Correspondence to: Dr Eduardo Parra, Biomedical Experimental Laboratory, Faculty of Sciences, University of Tarapaca, Avenida General Velásquez 1775, Arica, Chile

E-mail: eparra@uta.cl

Key words: JNK kinase, Tax protein, Jurkat leukemia cells, all-trans retinoic acid transactivator protein Tax transactivates the expression of several cellular genes in addition to the viral long term repeat (LTR) (3-5). The cellular genes activated by the Tax protein include several involved in cell growth which suggests that it is the expression of this protein that deregulates T-cell growth during HTLV-1 infection and that the constitutive expression of Tax is correlated with immortalization in T cells and the transformation of other cell types (6-9). Tax corresponds to a $40-\mathrm{kDa}$ transforming protein $(10,11)$ from the pathogenic retrovirus HTLV-1 that induces the expression of various family members of the transcription factor AP-1, such as c-Jun, Jun-D, c-Fos and Fra-1, at the level of RNA expression in T cells $(12,13)$. The Jun-N-terminal kinase (JNK) is the only member of the MAP kinases to phosphorylate c-Jun, the main component of AP-1 complexes, and also has ATF-2 and Elk-1 as substrates $(14,15)$. In mammalian cells, three mitogen-activated protein kinase (MAPK) families have been clearly characterized: namely classical MAPK (also known as ERK), c-Jun N-terminal kinase/stress-activated protein kinase (JNK/SAPK) and p38 kinase. The JNK group of MAPKs is activated in response to the treatment of cells with inflammatory cytokines and through exposure to environmental stress. JNK activation is mediated by a protein kinase cascade composed of a MAPK kinase and a MAPK kinase kinase (14-16). JNK and p38 kinases were initially proposed to mediate apoptosis in neuronal cells (17) and phosphorylation of c-Jun is necessary for neuronal cell death (18). The use of kinase inhibitors and the overexpression of dominant-negative mutant forms of MAPKs have demonstrated the involvement of JNK and/ or p38 kinase in apoptosis induced in non-neuronal cells by various stimuli, including estrogen, cisplatin, UV-B radiation and singlet oxygen $(19,20)$.

Retinoids are comprised of a group of compounds including retinoic acid (RA), vitamin $\mathrm{A}$ (retinol) and a series of natural and synthetic derivatives with A-like activity (21-24). Retinoids, including retinol and its analogues, are critical for a variety of biologic functions. Retinol is metabolized in retinal pigment epithelial cells to 11-cis-retinal and is required for normal ocular function (25); retinol and retroretinoids have also been implicated in maintaining and regulating immune function (26,27). Retinol is also essential for epithelial differentiation (28) and the control of embryonic development (29). The vast majority of retinoid-driven biologic effects are mediated by RAs, the active metabolites of retinol. All-trans retinoic acid 
(ATRA) and 9-cis-RA both play an important role in the regulation of gene transcription that ultimately results in the regulation of cell division, growth, differentiation and proliferation $(30,31)$. RAs exert their biologic activity by binding to nuclear receptors that regulate the transcriptional activity of a variety of target genes, which are implicated in the inhibition of cell growth, the induction of cell differentiation and the induction of apoptosis in a variety of tumor cell lines $(32,33)$.

Much of our understanding of the signaling events initiated following drug treatment has been based upon model cell systems. One of the most useful and widely studied of these $\mathrm{T}$ cell models has been the human Jurkat leukemia $\mathrm{T}$ cell line (34). Several studies have shown that Jurkat cells behave similar to normal cells $(35,36)$. Likewise, other studies have shown a correlation between JNK and the expression of interleukin (IL)-2, and interferon (IFN) $-\gamma$ in CD $4^{+} \mathrm{T}$ cells $(37,38)$. Using Jurkat cells as a model, we studied the effect of ATRA in decreasing the ability of the Tax protein to induce Jurkat cell proliferation as well as its correlation with the expression of JNK and a panel of cytokines such as IL-2, IFN- $\gamma$, IL-4 and IL-10.

\section{Materials and methods}

Reagents. ATRA was obtained from Sigma Chemical Co. (St. Louis, MO, USA). The protease inhibitors phenylmethylsulfonyl fluoride (PMSF), leupeptin, pepstatin, aprotinin and bestatin were purchased from Roche (USA); T4 polynucleotide kinase and poly $(\mathrm{dI}-\mathrm{dC}) 2$ were obtained from Amersham Pharmacia Biotech (Piscataway, NJ, USA). Tris-borate-EDTA buffer and acrylamide-bisacrylamide (29:1) were obtained from Bio-Rad (Richmond, CA, USA). Luciferase assay reagent, lysis buffer and the pGL-2 luciferase vector were obtained from Promega (Madison, WI, USA). TPA and ionomycin were purchased from Sigma Chemical Co. Anti-JNK, p38 and ERK antibodies were purchased from Santa Cruz Biotechnology, Inc. (Santa Cruz, CA, USA). MBP was purchased from Stratagene (La Jolla, CA, USA).

Cell culture and ATRA treatment. Jurkat T cells and Jurkat $\mathrm{T}$ cells expressing the Tax protein, were grown in RPMI-1640 containing $10 \%$ heat-inactivated fetal bovine serum (FBS), $200 \mathrm{mM}$ glutamine, nonessential amino acids, penicillin and streptomycin sulfate. Before ATRA treatment, cells were grown overnight $(16-20 \mathrm{~h})$ in medium containing $0.5 \%$ heatinactivated FBS and subsequently stimulated in the presence of the same medium with low concentrations of serum. ATRA was diluted in a culture medium containing $0.5 \%$ FBS, with the DMSO concentration below $0.5 \%$. Appropriate controls containing the same amount of solvent were included in each experiment. Intermittent passage in G418-containing medium was performed to ensure retention of the plasmid.

Plasmid construction and preparation of nuclear extracts. The plasmid expressing the wild-type Tax protein and the Tax inducible cell line were a gift from Dr Warner Greene (Gladstone Institute of Virology and Immunology, University of California, San Francisco, CA, USA). The human IL-2 promoter-enhancer fragment $(-500$ to +60$)$ was subcloned from plasmid SV-IL-2-CAT into the luciferase vector pGL2 (35).
The AP-1-luciferase reporter plasmid driven by the rat prolactin minimal promoter $(-36$ to +37$)$ under the control of four copies of the human AP-1 site (36) was kindly provided by M. Rincón and R. A. Flavell (Section of Immunobiology, Howard Hughes Medical Institute, Yale University School of Medicine, New Haven, CT, USA). Plasmids containing multimers of the recognition sites for NF- $\mathrm{NB}$ and AP-1 were constructed and linked to the pLuc-prolactin minimal promoter plasmid $(35,36)$. The orientation for each element was confirmed by the restriction enzyme cleavage. The tandem sequences used to construct the different plasmid multimers were as follows: i) four copies of the AP-1, 12-O-tetradecanoylphorbol-13-acetate (TPA), 5'-TCGATTGAGTCAGG-GTAA3'; ii) two copies of the $\mathrm{NF}-\kappa \mathrm{B}$-binding site of the human Ig $\kappa$ light-chain enhancer 5'-GGGACTTTCC-3'; iii) IL-2 promoter construct bearing a -500 to $+30(35)$.

Transient transfection and luciferase assays. Transfection of cells was conducted by electroporation, using an Electro Cell Manipulator 600 (BTX, San Diego, CA, USA) using $130 \mathrm{~V} / 1700 \mu \mathrm{F}$ capacitance. Briefly, 8x106 cells were transfected with $10 \mu \mathrm{g}$ of luciferase reporter plasmid and $5 \mu \mathrm{g}$ of each expression plasmid, and the mixture was incubated for $24 \mathrm{~h}$. Transfected cells were cultured in complete medium for $24 \mathrm{~h}$ and stimulated with ATRA or SP600125 for another $8 \mathrm{~h}$. Cells were harvested $32 \mathrm{~h}$ post-transfection, washed twice in phosphate-buffered saline (PBS) and treated with lysis buffer (luciferase assay; Promega) for 5-10 min on ice. Lysates were spun down for $1 \mathrm{~min}$, and the total supernatants were analyzed using luciferase reagent and measured as a duplicate in a luminometer (MicroLumat LB 96 P; Berthold) for 5 sec. Background measurement was subtracted from each duplicate, and experimental values were expressed either as recorded light units of luciferase activity or as relative activity compared with extracts from unstimulated cells $(35,36)$.

Preparation of nuclear extracts. Nuclear extracts, were prepared as previously described (34). The cells were grown at $37^{\circ} \mathrm{C}$ in a humidified atmosphere of $10 \% \mathrm{CO}_{2}$. Cells $\left(2 \times 10^{7}\right)$, incubated with $0.1 \%$ DMSO (control) or $30 \mathrm{nM} \mathrm{TPA}$, or $1 \mathrm{mM}$ ionomycin, were collected and washed with ice-cold PBS, washed again in buffer A [10 mM HEPES (pH 7.9), $15 \mathrm{mM}$ $\mathrm{KCl}, 2 \mathrm{mM} \mathrm{MgCl}{ }_{2}, 6 \mathrm{mM}$ DTT, $0.1 \mathrm{mM}$ EDTA and $1 \mathrm{mM}$ PMSF] and lysed in buffer A with $0.2 \%$ Nonidet P-40. The pelleted nuclei were re-suspended in buffer B [50 mM HEPES (pH 7.6), $50 \mathrm{mM} \mathrm{KCl,} 0.1 \mathrm{mM}$ EDTA, $1 \mathrm{mM}$ DTT, $1 \mathrm{mM}$ PMSF and $10 \%$ glycerol], in the presence of $0.3 \mathrm{M}\left(\mathrm{NH}_{4}\right)_{2} \mathrm{SO}_{4}$ (pH 7.9) and rocked for $30 \mathrm{~min}$ at $4^{\circ} \mathrm{C}$. The broken nuclei were centrifuged for $10 \mathrm{~min}$ at $100,000 \mathrm{x}$ g. A $125 \mu \mathrm{l}$ aliquot of supernatant was transferred to a second tube and additional $\left(\mathrm{NH}_{4}\right)_{2} \mathrm{SO}_{4}$ was added to a final concentration of $1.5 \mathrm{M}$ followed by a second centrifugation of 50,000 x $\mathrm{g}$ for $5 \mathrm{~min}$. The supernatant was removed and the pellet was re-suspended in $50 \mu \mathrm{l}$ of buffer $\mathrm{B}$ and stored at $70^{\circ} \mathrm{C}$. Protein concentration was estimated using the Bio-Rad stain protein assay kit with bovine albumin as the standard.

Western blot analysis. Jurkat cells $\left(5 \times 10^{7}\right)$ were seeded onto 6 -well plates. Forty-eight hours after transfection, the cells 
were collected and washed twice by cold PBS, and each well was treated with $50 \mathrm{ml}$ lysis buffer [ $2 \mathrm{mmol} / 1$ Tris- $\mathrm{HCl}$ (pH 7.4), $50 \mathrm{mmol} / 1 \mathrm{NaCl}, 25 \mathrm{mmol} / 1 \mathrm{EDTA}, 50 \mathrm{mmol} / \mathrm{l}$ $\mathrm{NaF}, 1.5 \mathrm{mmol} / 1 \mathrm{Na}_{3} \mathrm{VO}_{4}, 1 \%$ Triton $\mathrm{X}-100$ and $0.1 \%$ SDS], and supplemented with protease inhibitors $(1 \mathrm{mmol} / \mathrm{l}$ phenylmethylsulfonyl fluoride, $10 \mathrm{mg} / 1$ pepstatin, $10 \mathrm{mg} / 1$ aprotinin and $5 \mathrm{mg} / \mathrm{l}$ leupeptin) (all from Sigma Chemical Co.). Protein concentrations were determined using the Bradford protein assay. Equal amounts of protein $(50 \mathrm{mg}$ ) were separated on a $15 \%$ SDS polyacrylamide gel and transferred onto a nitrocellulose membrane (Hybond C; Amersham, Freiburg, Germany). Membranes were blocked in 5\% non-fat dry milk in TBS for $1 \mathrm{~h}$ at room temperature and probed with rabbit anti-JNK-1 (SC-1648) antibody (dilution 1:500; Santa Cruz Biotechnology, Inc.) overnight at $4^{\circ} \mathrm{C}$. After washing 3 times with TBS containing $0.1 \%$ Tween-20, membranes were incubated with anti-rabbit IgG horseradish peroxidase (1:5,000; Santa Cruz Biotechnology, Inc.) and developed by luminal mediated chemiluminescence (Appylgen Technologies, Inc., China). To confirm equal protein loading, membranes were reprobed with a 1:1,000 dilution of an anti-actin antibody (Santa Cruz Biotechnology, Inc.). Densitometric analyses were performed using Scion Image software $(39,40)$.

Labeling of apoptotic cells with Annexin V. Jurkat cells $(500,000)$ were treated with RA as indicated.Cells were washed with PBS and stained with Annexin V-FITC (Pharmingen) and propidium iodide (PI) in binding buffer [10 $\mathrm{mM}$ HEPES (pH 7.4), $140 \mathrm{mM} \mathrm{NaCl}$ and $2.5 \mathrm{mM} \mathrm{CaCl}_{2}$ ] or $15 \mathrm{~min}$ at room temperature in the dark. Cells were subsequently analyzed using flow cytometry (FACSCalibur) for apoptosis (FITC) and viability using PI.

Cytokine (IL-2, IL-4, IL-6 and IL-10) quantification in the culture supernatants. Jurkat leukemia T cells stably transfected with the Tax protein were cultured under a condition identical to that described for proliferation assay. ATRA was added at a final $10^{-7} \mathrm{M}$ concentration $36 \mathrm{~h}$ after the initiation of the culture in two independent pulses (every $12 \mathrm{~h}$ ). After $60 \mathrm{~h}$ of culture, supernatants were collected and the different cytokines were measured in triplicate by using an enzyme-linked immunosorbent assay (ELISA) system: IL-2, IL-4, IL-6 and IL-10 (R\&D Systems, Minneapolis, MN, USA) following the manufacturer's protocols.

\section{Results}

We examined the effect of ATRA treatment on the activity of one member of the MAP kinases in Jurkat leukemia and Jurkat leukemia Tax-expressing protein.

Inhibition of JNK activity by ATRA in Jurkat-Tax expressing cells occurs in a dose-dependent manner. We examined the effect of ATRA ( $4 \mu \mathrm{M})$ treatment on JNK kinase activity in Jurkat and Jurkat Tax-expressing cells. JNK-1 and JNK-2 activity was detected in both Jurkat and Jurkat Tax-expressing cells (Fig. 1A). The strong inhibition of JNK by ATRA, in Jurkat Tax-expressing cells occurred in a dose-dependent manner, ranging from 2 to $6 \mu \mathrm{M}$, compared with the untreated Jurkat cells (Fig. 1B). However, the effect of ATRA in the Jurkat
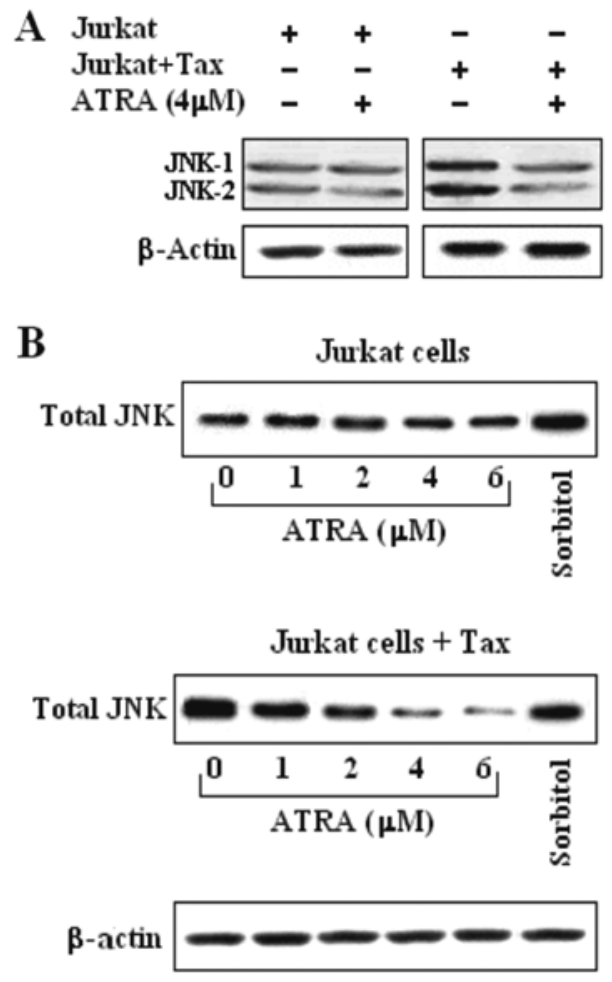

Figure 1. Effect of ATRA on the expression of JNK-1/JNK-2 protein, as assessed by western blot analysis with (A) antibodies directed to JNK-1 or/and JNK-2 or (B) antibodies to total JNK, to determine the level of the protein in Jurkat protein extracts after being separated by gel electrophoresis. Representative western blotting results are presented for Jurkat wild-type and/or Jurkat cells transfected with the Tax expression plasmid, with or without ATRA treatment. A representative blot of three is shown.

cells was lower than that observed in the untransfected Jurkat cells (Fig. 1B). The results obtained in the Jurkat and Jurkat Tax-expressing cells after $24 \mathrm{~h}$ of incubation are displayed in Fig. 1. Non-stimulated cells and cells treated with sorbitol were used as the control.

ATRA induces DEVDase activity Jurkat Tax-expressing cells. We investigated the effect of ATRA on the ability to induce caspase activity. Cells were pre-incubated in 10\% FCS for $16 \mathrm{~h}$ and were later treated with $8 \mu \mathrm{M}$ ATRA for different incubation times (Fig. 2A) and with increasing concentrations of ATRA (1-12 $\mu \mathrm{M}$ ) for $4 \mathrm{~h}$ (Fig. 2B). Cytosol extracts were prepared at the indicated periods of time, and caspase activity was subsequently measured using DEVD-AFC as a substrate. We demonstrated that the induction of DEVDase activity was clearly dependent on the time of incubation and the concentration level of ATRA. The increase in DEVDase activity was observed with concentrations of ATRA $>2 \mu \mathrm{M}$ in the Jurkat Tax-expressing cells. The presence of Annexin V-positive (apoptotic) cells was evident after $1 \mathrm{~h}$ of incubation with ATRA $(8 \mu \mathrm{M})$, and the number reached a maximum after $4 \mathrm{~h}$ (Fig. 2A). The apoptotic cells, dependent on ATRA concentration, as determined by Annexin V labeling, were evident following $2 \mu \mathrm{M}$ of ATRA treatment and the number of apoptotic cells reached a maximum level following $10 \mu \mathrm{M}$ ATRA treatment (Fig. 2B).

SP600125 and ATRA affect Tax upregulation of JNK in Jurkat Tax-expessing cells. We demonstrated that ATRA, at 
A All-trans retinoic acid induces DEVDase activity in Jukat - Tax cells

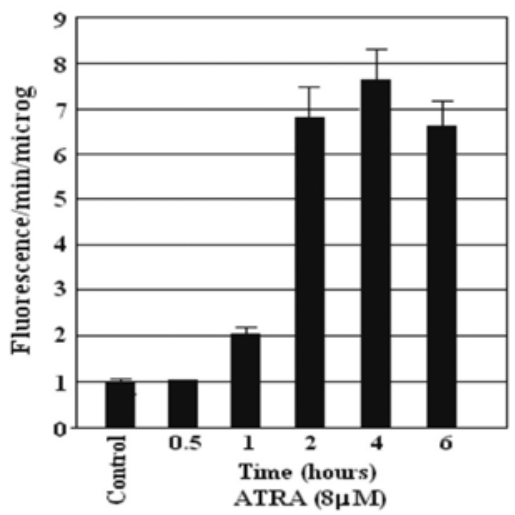

B All-trans retinoic acid induces DEVDase activity in Jukkat - Tax cells

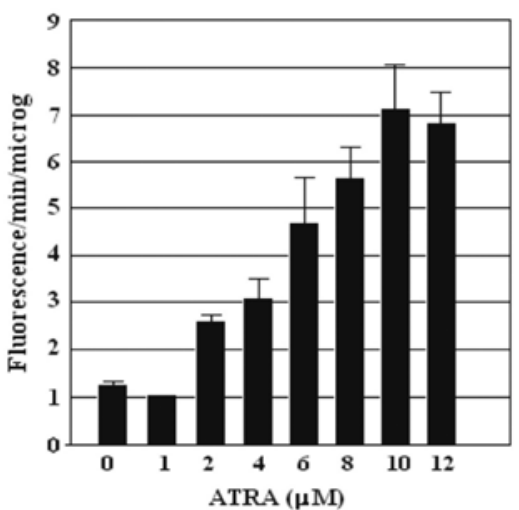

Figure 2. ATRA induces DEVDase activity in Jurkat Tax-expressing cells Jurkat cells transfected with the Tax expression plasmid were incubated (A) with $8 \mu \mathrm{M}$ ATRA for different periods of time and (B) in the presence of different concentrations of ATRA for $4 \mathrm{~h}$ and caspase activity was determined. The cells were lysed and protein extracts were prepared and subsequently analyzed for DEVDase activity. A representative experiment performed in triplicate is shown.

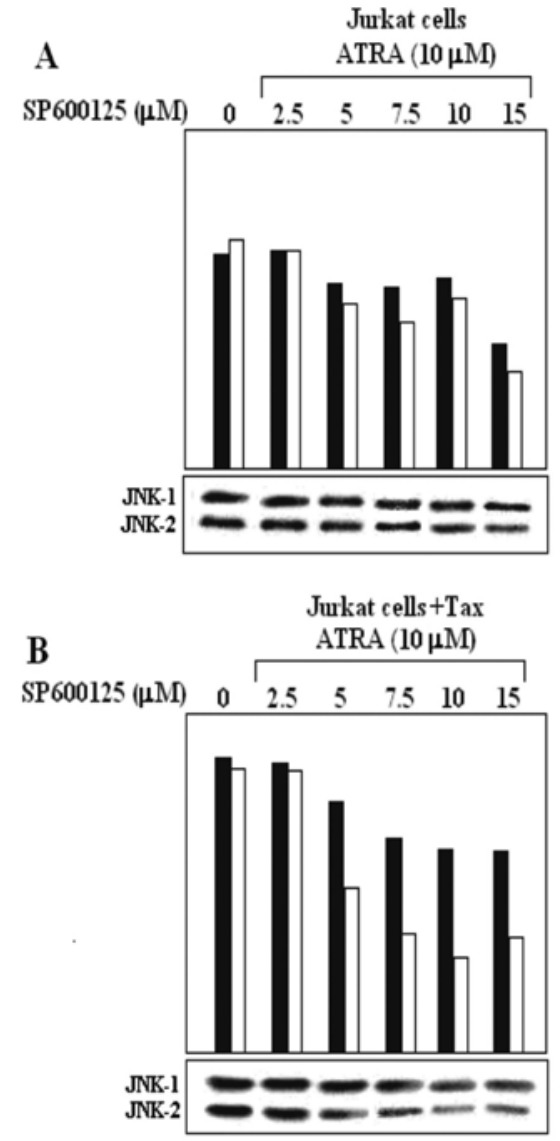

Figure 3. Effect of SP600125 in combination with ATRA, on the expression of JNK in Jurkat cells and Jurkat cells transfected with the wild-type Tax expression plasmid. (A) Jurkat and (B) Jurkat Tax-expressing cells, were treated with various concentrations of SP600125 $(2.5-15 \mu \mathrm{M})$ and with a constant concentration of ATRA $(10 \mu \mathrm{M})$ for $60 \mathrm{~min}$. After the treatments, a western blot assay was performed as described in Materials and methods. Aliquots $(50 \mu \mathrm{l})$ of total protein extract were subjected to SDS-PAGE followed by immunoblotting with the affinity-purified JNK antibody. A representative JNK western blotting of three separate experiments is shown.

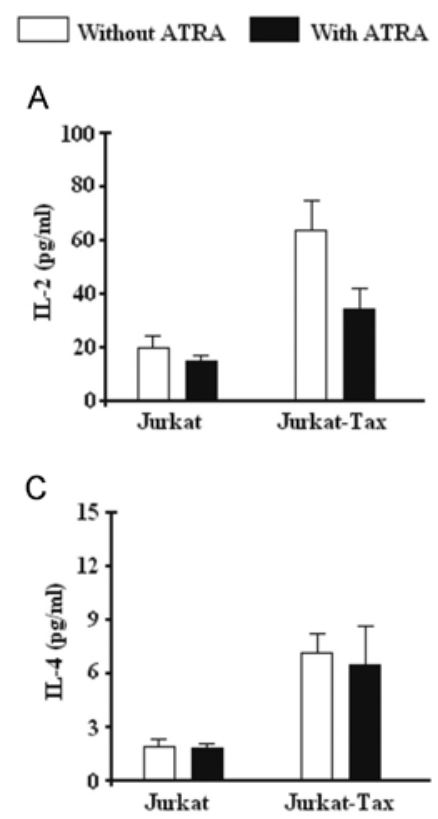

B

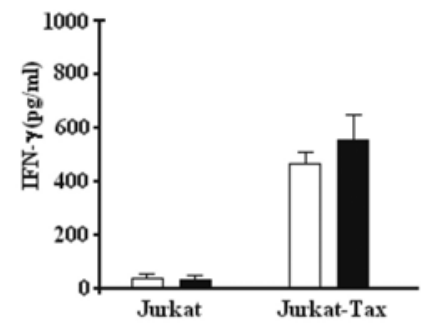

D

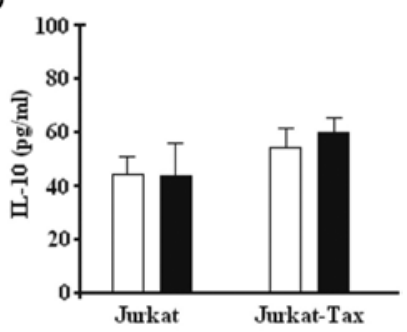

Figure 4. Effects of ATRA on the production of cytokines (A) IL-2, (B) IFN- $\gamma$, (C) IL-4 and (D) IL-10 by Jurkat and Tax-stimulated Jurkat cells. Jurkat cells and Jurkat cells transfected with the Tax expression plasmid were cultured in medium containing $10 \%$ FCS for $48 \mathrm{~h}$, in the absence (open bar) or presence (solid bar) of $8 \mu \mathrm{M}$ ATRA. Secretion of cytokines to the supernatants was measured by ELISA. Bars, SD in triplicate cultures of three similar experiments. 

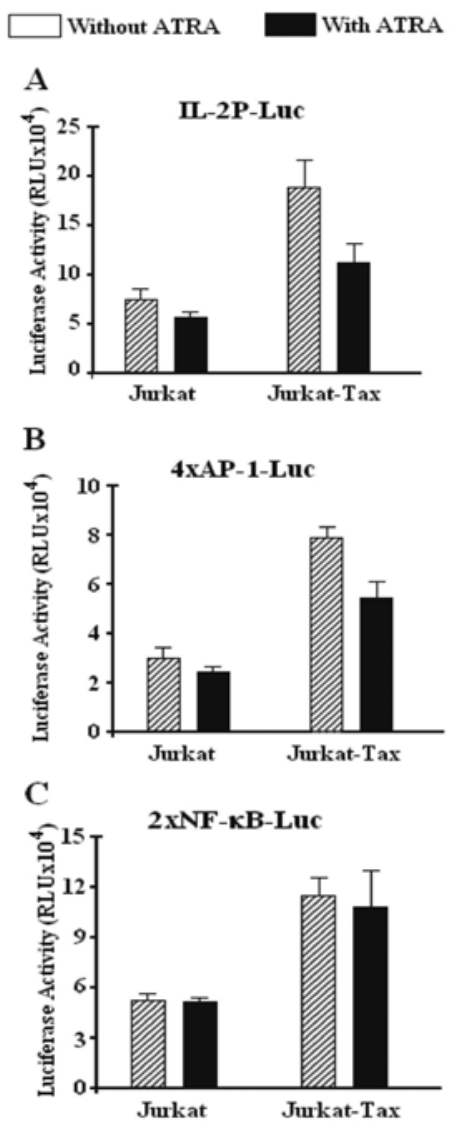

Figure 5. Transactivation of the IL-2 promoter and multimers of $4 x$ AP-1 and $2 \mathrm{x}$ NF- $\mathrm{kB}$ luciferase reporter constructs. Jurkat cells were transiently cotransfected or not with the Tax expression plasmid and (A) either with a human IL-2 promoter $(-500$ to +60$)$, or (B) a luciferase reporter construct containing four copies of the AP- 1 consensus sequence $(4 x$ CGATTGAGTCAGGGTAACG) or (C) with two copies of the NF- $\kappa$ B reporter construct (2x NF- $\kappa \mathrm{B}$; GGGACTTTCC consensus) and cultured or not in the presence of ATRA $8 \mu \mathrm{M}, 24 \mathrm{~h}$ post-transfection. Luciferase assay is expressed as relative luminescence units (RLU) minus background units alone. All sets of results shown are the mean values from three similar experiments. Error bars indicate the standard error of the mean.

concentration levels of 2-6 $\mu \mathrm{M}$, was able to decrease JNK expression in Jurkat and Jurkat Tax-expressing cells (Fig. 1B). To further study the inhibitory effect of ATRA on the expression of JNK, we performed a combination assay using ATRA and SP600125 in untransfected Jurkat cells (Fig. 3A) and Jurkat cells transfected with a plasmid expressing the Tax protein (Fig. 3B). The effect of increasing concentrations of SP600125 on ATRA-mediated inhibition of JNK expression in Jurkat Tax-expressing cells was further investigated. Jurkat and Jurkat Tax-expressing cells were pre-incubated with increasing concentrations of SP600125 (2.5, 5.0, 7.5, 10 and $15 \mu \mathrm{M}$ ) for $120 \mathrm{~min}$. Then, $10 \mu \mathrm{M}$ ATRA was added and cells were incubated for an additional $180 \mathrm{~min}$. Cell extracts were prepared and subsequently assayed using a western blot assay for JNK-1 and JNK-2 protein expression. We increased the ATRA concentration to $10 \mu \mathrm{M}$, to reach a major inhibitory effect of JNK-1 expression. The combination treatment of ATRA with SP600125 further decreased the JNK expression protein. Both ATRA and SP600125 treatments reduced the activity of JNK-1 and JNK-2 (Fig. 3A and B). ATRA-mediated inhibition of JNK-1/JNK-2 expression in untransfected Jurkat cells was lower (Fig. 3A) compared to that observed in Jurkat cells transfected with the Tax protein expression plasmid (Fig. 3B). The expression of JNK-1 was almost completely inhibited with increasing concentrations of SP600125 $(15 \mu \mathrm{M})$ and ATRA (10 $\mu \mathrm{M})$ (Fig. 3B).

Regulation of cytokine production by ATRA in Jurkat and Jurkat Tax-expressing cells. To further understand the effect of ATRA, cytokine induction and secretion experiments were performed in Jurkat and Jurkat Tax-expressing cells for IL-2, IL-4, IFN- $\gamma$ and IL-10. A strong induction of IL-2 (Fig. 4A), IFN- $\gamma$ (Fig. 4B) and IL-4 (Fig. 4C) production in Jurkat-Tax cells, compared with Jurkat cells were observed, but not for IL-10 (Fig. 4D). The mean secretion of IL-2 was statistically decreased in Jurkat Tax-expressing cells, but not for IFN- $\gamma$, IL-4 and IL-10 when ATRA was added to the Jurkat Tax-expressing stimulated cell culture.

Tax transfection strongly enhances transcriptional activity of three luciferase reporter constructs expressing the $I L-2$ promoter, $A P-1$ and $N F-\kappa B$ reporter construct. Jurkat and Jurkat T cells expressing the Tax protein were transiently co-transfected with luciferase plasmid reporter constructs containing the inducible region of the IL-2 enhancer/promoter $(-500$ to +60$)$ (Fig. 5A) or an AP-1 (Fig. 5B), or an NF- $\kappa$ B (Fig. 5C) reporter construct. Tax expression was required to induce high transcription of these constructs. The effect observed after Tax expression was 3-to 4-fold higher in all three constructs, the IL-2 promoter, the AP-1- and the NF- $\mathrm{B}$-driven transcription, compared with untransfected Jurkat cells which showed a moderate transcriptional activity. However, after ATRA treatment the activity of the IL-2 promoter (Fig. 5A) and AP-1 reporter construct (Fig. 5B) was strongly affected decreasing the transcriptional activity of both the IL-2 promoter and the AP-1 reporter, but failed to affect and slightly decreased the transcriptional activity of the $\mathrm{NF}-\kappa \mathrm{B}$ reporter construct promoter (Fig. 5C). Noteworthy, NF- $\kappa \mathrm{B}$-driven transcription in the Tax-transfected and untransfected Jurkat cells was not affected by ATRA (Fig. 5C). Apparently, NF- $\kappa$ B was not a target for ATRA, since no activity was noted in Jurkat cells transfected or not with the Tax-expression plasmid.

\section{Discussion}

In the present study, the effect of ATRA alone or in combination with SP600125 on human Jurkat leukemia T cells, transfected or not with a Tax expression plasmid was studied. We demonstrated that ATRA in concentration levels between 4 to $10 \mu \mathrm{M}$, caused a significant and sustained decreasing effect on JNK expression in Jurkat Tax-expressing cells. A slight effect in all the assays performed was observed in untransfected Jurkat cells. Although the action of retinoids on human cells has been previously studied (26-29), conclusive results have not been obtained. JNK inactivation in Tax cells correlated with the induction of apoptosis, as determined by the measurement of DEVDase activity in the cells treated with ATRA. In addition, the inhibitory effect of ATRA was further increased by simultaneous stimulation with SP600125, a strong inhibitor of JNK. Several in vitro studies have shown that JNK signaling plays an important role in enhancing cell 
viability and cell cycle progression of several cancer cell types $(17,18,39)$. Extensive studies on several other cell lines have shown that the inhibition of JNK by SP600125 leads to G2/M cell cycle arrest $(19,20,40)$. To further analyze the molecular mechanism of ATRA-mediated suppression of the Tax protein in Jurkat cells we studied its effects on the expression of IL-2, IFN- $\gamma$, IL-10 and IL-4, before and after ATRA treatment. The effect of retinoids in specific cytokine induction has been widely investigated in different cellular lineages with contradictory results $(26-28,41)$. ATRA inhibition of JNK may be explained by a putative regulation of the events mediated by IL-2 and/or IFN- $\gamma$. To address this issue, IL-2, IL-4, IL-10 and IFN- $\gamma$ were measured in the supernatant of Jurkat cells with or without ATRA treatment $(8 \mu \mathrm{M})$. Tax expression strongly activated IL-2 and IFN- $\gamma$ production but failed to substantially increase the activity of IL-4 and IL-10. However, ATRA treatment was able to moderately decrease the production of IL-2 and failed to decrease the production of IFN- $\gamma$. Only a slight Tax-mediated IL-4 and IL-10 increase was observed in all tested cells.

To further understand the effect of ATRA on Tax-expressing cells, we performed a luciferase assay with reporter constructs for IL-2 promoter-Luc, AP-1-Luc and NF-kB-Luc. The results showed that the addition of ATRA reduced the activity of the IL-2 promoter and AP-1 reporter construct, but failed to reduce the activity of the NF- $\mathrm{kB}$ reporter construct, suggesting that the activity of ATRA may occur through AP-1. Previous studies have demonstrated that the Tax response of the IL- $2 \mathrm{R}$ $\alpha$ chain promoter and the HIV LTR is mediated by the activation of NF- $\mathrm{KB}(42,43)$. Tax has been shown to increase the expression of NF- $\mathrm{KB}$ proteins and to prolong its localization to the nucleus where it is transcriptionally active $(44,45)$. Tax also interacts specifically with IкB proteins (46).

In this context, IL-2 promoters have both NF- $\mathrm{KB}$ and AP-1 binding sites (47) which are important for promoter activity $(48,49)$. The AP-1 transcription factor is composed of Jun and Fos proteins that function as transcriptional regulators in a heterodimeric complex (49). The formation of heterodimers is performed by the JNK kinase, which phosphorylates cJun allowing it to bind to c-Fos and form the complex AP-1 (50). Thus, the modulation of JNK may be responsible for decreasing Tax activity observed in Jurkat cells treated with ATRA. Tax-expressing cells prior to treatment resulted in an increase of IL-2 transcription and expression. However, our results demonstrated that cells treated with ATRA demonstrated a decrease in both the transcription and expression of IL-2. Using reporter constructs for AP-1 and NF- $\mathrm{KB}$, two nuclear factors presented in the IL-2 promoter, revealed that ATRA specifically downregulated AP-1, but not NF- $\mathrm{kB}$ response element activities, compared with the untreated cells. These results strongly correlate with the decrease of JNK-1 and JNK-2 expression, suggesting that the Tax protein may regulate the development and function of Tax-expressing cells involved in cell-mediated response, partly by inhibiting factors required for the transcription of the IL-2 gene such as AP-1, a target of JNK activity.

\section{Acknowledgements}

We gratefully acknowledge Dr Warner Greene (Gladstone Institute of Virology and Immunology, University of California,
San Francisco, CA, USA) for providing the plasmid expressing the wild-type Tax protein and the Tax inducible cell line. This study was supported by the Biomedical Experimental Laboratory, Faculty of Sciences, University of Tarapaca, Arica, Chile.

\section{References}

1. Poiesz BJ, Ruscetti FW, Gazdar AF, Bunn PA, Minna JD and Gallo RC: Detection and isolation of type $C$ retrovirus particles from fresh and cultured lymphocytes of a patient with cutaneous T-cell lymphoma. Proc Natl Acad Sci USA 77: 7415-7419, 1980.

2. Hinuma V, Nagata K, Hanaoka M, Nakai M, Matsumoto T, Kinoshita K, Shirakawa S and Miyoshi I: Adult T-cell leukemia antigen in ATL cell line and detection of antibodies to the antigen in human sera. Proc Natl Acad Sci USA 78: 6476-6480, 1981.

3. Cann AJ, Rosenblatt JD, Wachsman W, Shah NP and Chen IS: Identification of the gene responsible for human T-cell leukaemia virus transcriptional regulation. Nature 318: 571-574, 1985.

4. Felber BK, Paskalis H, Kleinman-Ewing C, Wong-Staal F and Pavlakis GN: The $\mathrm{pX}$ protein of HTLV-I is a transcriptional activator of its long terminal repeats. Science 229: 675-679, 1985.

5. Sodroski J, Rosen C, Goh WC and Haseltine W: A transcriptional activator protein encoded by the $\mathrm{x}$-lor region of the human T-cell leukemia virus. Science 228: 1430-1434, 1985.

6. Grassmann R, Berchtold S, Radant I, Alt M, Fleckenstein B, Sodroski JG, Haseltine WA and Ramstedt U: Role of human T-cell leukemia virus type $1 \mathrm{X}$ region proteins in immortalization of primary human lymphocytes in culture. J Virol 66: 4570-4575, 1992.

7. Siekevitz M, Feinberg MB, Holbrook N, Wong-Staal F and Greene WC: Activation of interleukin 2 and interleukin 2 receptor (Tac) promoter expression by the trans activator (tat) gene product of human T-cell leukemia virus, type I. Proc Natl Acad Sci USA 84: 5389-5393, 1987.

8. Ballard DW, Bohnlein E, Lowenthal JW, Wano Y, Franza BR and Greene WC: HTLV-I tax induces cellular proteins that activate the kappa B element in the IL-2 receptor alpha gene. Science 241 : 1652-1655, 1988.

9. Leung KY and Nabel GJ: HTLV-1 transactivator induces interleukin-2 receptor expression through an NF-kappa B-like factor. Nature 333: 776-778, 1988.

10. Franchini G: Molecular mechanisms of human T-cell leukemia/ lymphotropic virus type I infection. Blood 86: 3619-3639, 1995.

11. Franklin A and Nyborg JK: Mechanisms of Tax regulation of human T cell leukemia virus type I gene expression. J Biomed Sci 2: 17-29, 1995.

12. Bergers G, Graninger P, Braselmann S, Wrighton $C$ and Busslinger M: Transcriptional activation of the fra-1 gene by AP-1 is mediated by regulatory sequences in the first intron. Mol Cell Biol 15: 3748-3758, 1995.

13. Angel P and Karin M: The role of Jun, Fos and the AP-1 complex in cell-proliferation and transformation. Biochim Biophys Acta 1072: 129-157, 1991

14. Fuchs SY, Xie B, Adler V, Fried VA, Davis RJ and Ronai Z: c-Jun NH2-terminal kinases target the ubiquitination of their associated transcription factors. J Biol Chem 272: 32163-32168, 1997.

15. Yao M, Nguyen TV and Pike CJ: Beta-amyloid-induced neuronal apoptosis involves c-Jun N-terminal kinase-dependent downregulation of Bcl-w. J Neurosci 25: 1149-1158, 2005.

16. Widmann C, Gibson S, Jarpe MB and Johnson GL: Mitogenactivated protein kinase: conservation of a three-kinase module from yeast to human. Physiol Rev 79: 143-180, 1999.

17. Xia Z, Dickens M, Raingeaud J, Davis RJ and Greenberg ME: Opposing effects of ERK and JNK-p38 MAP kinases on apoptosis. Science 270: 1326-1331, 1995.

18. Behrens A, Sibilia M and Wagner EF: Amino-terminal phosphorylation of c-Jun regulates stress-induced apoptosis and cellular proliferation. Nat Genet 21: 326-329, 1999.

19. Zhang CC and Shapiro DJ: Activation of the $\mathrm{p} 38$ mitogen-activated protein kinase pathway by estrogen or by 4-hydroxytamoxifen is coupled to estrogen receptor-induced apoptosis. J Biol Chem 275: 479-486, 2000

20. Yu R, Mandlekar S, Tan TH and Kong AN: Activation of p38 and c-Jun N-terminal kinase pathways and induction of apoptosis by chelerythrine do not require inhibition of protein kinase C. J Biol Chem 275: 9612-9619, 2000. 
21. Brockes J: Developmental biology. Reading the retinoid signals. Nature 345: 766-768, 1990.

22. Maden M: The retinoic acid supergun affair. Curr Biol 4 : 281-284, 1994

23. O'Connell MJ, Chua R, Hoyos B, Buck J, Chen Y, Derguini F and Hammerling UJ: Retro-retinoids in regulated cell growth and death. Exp Med 184: 549-555, 1996.

24. Chen Y, Buck J and Derguini F: Anhydroretinol induces oxidative stress and cell death. Cancer Res 59: 3985-3990, 1999.

25. Duester G: Families of retinoid dehydrogenases regulating vitamin A function: production of visual pigment and retinoic acid. Eur J Biochem 267: 4315-4324, 2000.

26. Yan JP, Garrus JE, Giebler HA, Stargell LA and Nyborg JK: Molecular interactions between the coactivator CBP and the human T-cell leukemia virus Tax protein. J Mol Biol 281: 395-400, 1998.

27. Cantorna MT, Nashold FE, Chun TY and Hayes CE: Vitamin A down-regulation of IFN-gamma synthesis in cloned mouse Th1 lymphocytes depends on the CD28 costimulatory pathway. J Immunol 156: 2674-2679, 1996.

28. De Luca LM, Darwiche N, Celli G, et al: Vitamin A in epithelial differentiation and skin carcinogenesis. Nutr Rev 52: S45-S52, 1994.

29. Thaller $\mathrm{C}$ and Eichele G: Identification and spatial distribution of retinoids in the developing chick limb bud. Nature 327: 625-628, 1987.

30. Saari JC: Retinoids in photosensitive systems. In: The Retinoids: Biology, Chemistry, and Medicine. Sporn MB, Roberts AB and Goodman DS (eds). 2nd edition. Raven, New York, NY, pp351-386, 1994

31. Sporn MB and Roberts AB: Role of retinoids in differentiation and carcinogenesis. J Natl Cancer Inst 73: 1381-1387, 1984.

32. Martin SJ, Bradley JG and Cotter TG: HL-60 cells induced to differentiate towards neutrophils subsequently die via apoptosis. Clin Exp Immunol 79: 448-453, 1990

33. Oridate N, Lotan D, Xu XC, Hong WK and Lotan R: Differential induction of apoptosis by all-trans-retinoic acid and N-(4hydroxyphenyl) retinamide in human head and neck squamous cell carcinoma cell lines. Clin Cancer Res 2: 855-863, 1996.

34. Sigal HN and Dumont FJ: Cyclosporin A, FK-506, and rapamycin: pharmacologic probes of lymphocyte signal transduction. Ann Rev Immunol 10: 519-560, 1992.

35. Parra E, Varga M, Hedlund G, Kalland T and Dohlsten $M$ Costimulation by B7-1 and LFA-3 targets distinct nuclear factors that bind to the interleukin-2 promoter: B7-1 negatively regulates LFA-3-induced NF-AT binding. Mol Cell Bio 17: 1314-1323, 1997.

36. Parra E, McGuire K, Hedlund G and Dohlsten M: Overexpression of RelA and c-Jun substitutes for B7-1 costimulation by targeting the CD28RE within the IL-2 promoter. J Immunol 160: 5374-5381, 1998.

37. Smeets RL, Fleuren WM, He X, Vink PM, Wijnands F, Gorecka M, Klop H, Bauerschmidt S, et al: Molecular pathway profiling of $\mathrm{T}$ lymphocyte signal transduction pathways; Th1 and Th2 genomic fingerprints are defined by TCR and CD28mediated signalling. BMC Immunol 13: 12, 2012.
38. Rincón M, Conze D, Weiss L, Diehl NL, Fortner KA, Yang D, Flavell RA, Enslen H, Whitmarsh A and Davis RJ: Conference highlight: do T cells care about the mitogen-activated protein kinase signalling pathways? Immunol Cell Biol 78: 166-175, 2000.

39. Parra E, Ortega A and Saenz L: Downregulation of Egr-1 by siRNA inhibits growth of human prostate carcinoma cell line PC-3. Oncol Rep 22: 1513-1518, 2009.

40. Parra E: Activation of MAP kinase family members triggered by TPA or ionomycin occurs via the protein phosphatase 4 pathway in Jurkat leukemia T cells. Mol Med Rep 5: 773-778, 2012.

41. Allende LM, Corell A, Madroño A, Góngora R, RodríguezGallego C, López-Goyanes A, Rosal M and Arnaiz-Villena A: Retinol (vitamin A) is a cofactor in CD3-induced human T-lymphocyte activation. Immunology 90: 388-396, 1997.

42. Kanno T, Franzoso G and Siebenlist U: Human T-cell leukemia virus type I Tax-protein-mediated activation of NF-kappa B from p100 (NF-kappa B2)-inhibited cytoplasmic reservoirs. Proc Natl Acad Sci USA 91: 12634-12638, 1994.

43. Maggirwar SB, Harhaj E and Sun SC: Activation of NF-kappa B/ Rel by Tax involves degradation of I kappa $B$ alpha and is blocked by a proteasome inhibitor. Oncogene 11: 993-998, 1995.

44. Suzuki T, Hirai H, Murakami T and Yoshida M: Tax protein of HTLV-I destabilizes the complexes of NF-kappa B and I kappa B-alpha and induces nuclear translocation of NF-kappa B for transcriptional activation. Oncogene 10: 1199-1207, 1995.

45. Suzuki T, Hirai H and Yoshida M: Tax protein of HTLV-I interacts with the Rel homology domain of NF-kappa B p65 and a c-Rel protein bound to the NF-kappa B binding site and activates transcription. Oncogene 9: 3099-3105, 1994.

46. McGuire KL, Curtiss VC, Larson EL and Haseltine WA Influence of human T-cell leukemia virus type I tax and rex on interleukin-2 gene expression. J Virol 67: 1590-1599, 1993.

47. Visse E, Inostroza J, Cabello G and Parra E: The MAP kinases are differently utilized by CD28 and CD2 adhesion pathways in superantigen-activated Jurkat T cells. Biol Res 36: 263-278, 2003.

48. Olsson C, Michaelsson E, Parra E, Pettersson U, Lando P and Dohlsten M: Biased dependency of CD80 versus CD86 in the induction of transcription factors regulating the IL-2 promoter. Int Immunol 10: 499-506, 1998.

49. Lee W, Mitchell P and Tjian R: Purified transcriptional factor AP-1 interacts with TPA-inducible enhancer elements. Cell 49: 741-752, 1987.

50. Bannister A, Oehler T, Wilhelm D, Angel P and Koumanidis T: Stimulation of c-Jun activity by CBP: c-Jun residues Ser63/73 are required for $\mathrm{CBP}$ induced stimulation in vivo and $\mathrm{CBP}$ binding in vitro. Oncogene 11: 2509-2514, 1995. 